\title{
Gusto, propiedad e intrusión. Algunos aspectos de la cultura de masas en tres cuentos de Silvina Ocampo (1959-1970)
}

\author{
Taste, Property and Intrusion. Some Aspects of Mass Culture \\ in Three Selected Stories by Silvina Ocampo (1959-1970) \\ Gosto, propriedade e intrusão. Alguns aspectos da cultura \\ de massa em três contos de Silvina Ocampo (1959-1970)
}

\section{María de los Ángeles Mascioto}

UNIVERSIDAD NACIONAL DE LA PLATA, ARGENTINA

Docente en la Universidad Nacional de La Plata, doctora en Letras (UNLP) y becaria de investigación en CONICET (Argentina). Entre sus últimas publicaciones en revistas especializadas se enumeran: "Borges editor" (Anclajes, 2018); "La prensa del siglo XIX en las primeras historias de la literatura argentina y brasileña (1916-1922)" (Cuadernos Americanos, 2017), y "Pistas del Detection Club en la sección Cuento policial de la Revista Multicolor de los Sábados: entre Borges y Crítica" (Rilce. Revista de Filología Hispánica, 2017). Correo electrónico: mariamascioto@gmail.com

\footnotetext{
Artículo de investigación

Una primera versión de este trabajo formó parte de la tesis de la autora: "Sociedad y cultura de masas en la cuentística de Silvina Ocampo (1959-1970)", para la obtención del grado de Licenciada en Letras en la Universidad Nacional de La Plata (2010), aprobada con nota 10 (diez), con recomendación de publicación. Documento accesible en línea desde la siguiente dirección: http://revistas.javeriana.edu.co
} 


\section{Resumen}

El propósito de este artículo es analizar la relación entre propiedad, gusto y cultura de masas en tres relatos de Silvina Ocampo publicados en $L a$ furia (1959) y Los días de la noche (1970). Propongo como hipótesis que, en estos tres cuentos, publicados durante el período postperonista, la cultura masiva se entromete en la vida privada de los personajes mediante la adquisición compulsiva y acumulativa de objetos kitsch, la repetición de frases hechas y clichés, el discurso de la prensa escrita o radiofónica y algunos tópicos pertenecientes a los géneros masivos.

Palabras clave: literatura argentina; cultura de masas; Silvina Ocampo; kitsch

\section{Abstract}

The purpose of this article is to analyze the relation between the concepts of property, taste and mass culture in three stories by Silvina Ocampo published in La furia (1959) and Los días de la noche (1970). I propose as a hypothesis that in these three stories, published during the post-Peron period, mass culture intrudes in the private life of the characters through the compulsive and cumulative acquisition of kitsch objects, the repetition of set phrases and clichés, the discourse of the written press and the radio, as well as other topics belonging to the massive genres.

Keywords: Argentine literature; mass culture; Silvina Ocampo; kitsch

\section{Resumo}

O propósito deste artigo é analisar a relação entre propriedade, gosto e cultura de massa em três relatos de Silvina Ocampo publicados em La furia (1959) e Los días de la noche (1970). Proponho como hipótese que nestes três contos, publicados durante o período pós-peronista, a cultura massiva intromete-se na vida privada dos personagens mediante a aquisição compulsiva e cumulativa de objetos kitsch, a repetição de frases feitas e clichês, o discurso da imprensa escrita ou radiofónica e alguns tópicos pertencentes aos géneros massivos.

\section{Palavras-chave: literatura} argentina; cultura de massa; Silvina Ocampo; kitsch

\section{Cómo citar este artículo:}

Mascioto, María de los Ángeles. "Gusto, propiedad e intrusión. Algunos aspectos de la cultura de masas en tres cuentos de Silvina Ocampo (1959-1970)". Cuadernos de Literatura 22.44 (2018): 204-222. https://doi.org/10.11144/Javeriana.cl22-44.gpia 
"SosPecho QUE ESTOY heredando la vida de alguien" (Ocampo, La furia y otros cuentos 56 ) dice Cristina, la protagonista de "La casa de azúcar" (La furia, 1959), cuando su esposo comienza a advertir cambios en sus gustos. Una herencia parecida es la que recibe la empleada doméstica de "La propiedad" (La furia, 1959): su patrona no solo le regala todo aquello que deja de usar, sino que tras su muerte le cederá: "una pequeña fortuna, a condición de que cuides esta casa" (La furia y otros cuentos 103). Al igual que ella, Herminia, la protagonista de "Las esclavas de las criadas" (Los días de la noche, 1970), dice tener una fidelidad intachable hacia su "ama", atributo que le permite salvarle la vida: "-Dios concede a Herminia todo lo que le pide. Es una perla. Ha prolongado mi vida" (Los días de la noche 67). Los tres cuentos están enmarcados en los límites de una casa. Las respectivas dueñas son observadas por narradores que vigilan las mutaciones en sus gustos y costumbres a partir de la penetración de intrusos al hogar. Según Bourdieu (2000), la casa expresa el estado presente y pasado de los que la ocupan, la riqueza heredada, la presencia de nuevos ricos o la pobreza. En estos tres cuentos la cultura de $\operatorname{masas}^{1}$ se hace presente mediante la retórica del inventario y la relación $k i t s c h^{2}$ entre el sujeto y los

1 El concepto "cultura de masas" hace referencia a un fenómeno cuyos productos culturales son reproducidos por medios técnicos y dirigidos a un público considerable en cantidad. Se trata de una noción genérica y ambigua que se ha ido definiendo desde las primeras décadas del siglo XX a través de un extenso recorrido intelectual que analizó los efectos positivos o negativos del proceso de industrialización, el desarrollo de la sociedad burguesa y la progresiva evolución de los medios de comunicación, entre los diversos factores que marcaron el avance de la modernidad. Las querellas en torno a este tema han provocado en algunos casos rechazo, en otros, aceptación, tomando la forma de una discusión política y ética (Zubieta 117).

2 Adriana Mancini ha observado que muchas de las narraciones de La furia (1959) presentan personajes de clase media rodeados de artículos kitsch hacia los que demuestran un sentimentalismo exacerbado que llevaría a desenlaces fatales como la alienación, la muerte o la locura. Asimismo, señala que: "si aceptamos que en los cuentos los personajes se entregan a la cursilería para amortiguar las desdichas cotidianas, también hay en ellos señas que delatan el riesgo de quedar entrampados en la telaraña de las cosas" ("Silvina Ocampo" 245). En este sentido, la misma Silvina Ocampo ha afirmado: "La cursilería siempre me atrajo, es una forma del horror. No puedo dejar de mirar los objetos cursis, me causan gracia y me horripilan al mismo tiempo" (tomado de Mancini, Escalas de pasión 51). En relación con esto, Molloy también destaca en los relatos ocampianos una mirada que señala, fascinada, las pequeñas manías, la vulgaridad, la cursilería; no para denunciarlas ácidamente como lo haría Flaubert, tampoco para compadecerse de ellas, 
objetos que rodean la intimidad de su micromundo: la casa. Se establece un juego de tensiones entre las empleadas domésticas, presentadas como herederas "legítimas" de los bienes de sus respectivas patronas, y los "recién llegados", personajes que pretenderían incorporarse al grupo de los poseedores genuinos.

La importancia que se le da al gusto en estos cuentos se refleja en las tensiones entre ser y parecer, originalidad y estandarización y se traduce en el discurso literario mediante el empleo de clichés y lugares comunes que promueven la despetrificación de los códigos marcados por la convención. Teniendo en cuenta que a través de los objetos lo que habla es una sociedad estratificada, en estos relatos las perspectivas estéticas que suponen, por ejemplo, la cosmética corporal, la vestimenta, la decoración doméstica, los gustos culinarios, constituirán una ocasión de probar o afirmar la posición ocupada en el espacio social como una categoría que se debe tener o una distancia que corresponde mantener (Bourdieu La distinción). ${ }^{3}$

Por otra parte, el juego entre protección y peligro en la acumulación de objetos de consumo podría relacionarse con lo que Abraham Moles ha identificado como una oposición entre "Kitsch dulce y agrio". Ambos implican respectivamente la oposición freudiana del instinto sexual y el instinto de muerte: el kitsch dulce es azucarado, algunos de sus ejemplos son las muñecas de color rosa carne, los monumentos de azúcar en los escaparates de las confiterías; mientras que en el extremo opuesto encontramos como exponentes del kitsch agrio los cráneos mexicanos y el vampirismo del cine de horror (Moles, Los objetos 169).

sino que lo que en Flaubert podría ser punto de partida crítico, en Ocampo sería puro lugar literario (Las invitadas 217-218). Esto coincide con el análisis de Mancini respecto de lo cursi como un elemento integral de la estética ocampiana, cuyos estadios son el goce, la promesa de felicidad, la alienación, el peligro y, en el límite, un intento de huída, todos los cuales marcarían disímiles actitudes de los personajes emplazados en espacios que se tematizan y enfrentados a objetos que se animizan (Escalas de pasión 52 ).

3 En concordancia con esto, la mayor parte de los relatos de Silvina Ocampo publicados en el periodo posterior al segundo gobierno peronista -nos referimos a las colecciones La furia (1959), Las invitadas (1961) y Los días de la noche (1970)- incluyen formas de la cultura de masas, acompañadas por el uso de registros populares. En ellos se representa un ambiente pequeño-burgués mediante la descripción o enumeración detallada de estereotipos culturales, la presencia de lugares comunes o clichés y de una estética Kitsch (Cfr. Mascioto). 


\section{La propiedad antes de la intromisión: edén de felicidad}

En "La casa de azúcar", antes de que los protagonistas conocieran la vivienda, incluso antes de casarse, Cristina -una mujer perteneciente a la pequeña burguesía $-^{4}$ tenía supersticiones que, según su cónyuge, no la dejaban vivir. No se trataba del miedo a la muerte -como le ocurre a su marido-,${ }^{5}$ sino que más bien se asociaban al temor de convertirse en otra persona. Esto se comprueba en el carácter imperativo y prohibitivo de las supersticiones que giraban en torno a sus gustos: no debía usar otra ropa que no fuese la que usaba siempre -el narrador señala: "llevaba puesto un vestido verde que siguió usando hasta que se le rompió, pues me dijo que le traía suerte y que cuando se ponía otro, azul, que le sentaba mejor, no nos veíamos" (Ocampo, La furia y otros cuentos 49)-; tenía vedado comprar ciertas cosas, escuchar cierta música, pasar por algunos lugares: "No podía comprar frutillas en el mes de diciembre, ni oír determinadas músicas, ni adornar la casa con peces rojos, ${ }^{6}$ que tanto le gustaban. Había ciertas calles que no podíamos cruzar, ciertas personas, ciertos cinematógrafos que no podíamos frecuentar" (49). Estas prohibiciones son de carácter cultural, se relacionan directamente con los gustos de Cristina y con los que no está permitido que tenga. El vínculo entre gusto e identidad social nos permite pensar en aquellos como afirmaciones prácticas de una diferencia inevitable: cuando tienen que justificarse, se afirman de manera enteramente negativa, por medio del rechazo de otros gustos. Siguiendo a Bourdieu ( $L a$ distinción) podemos definir los gustos ante todo como "disgustos", que producen una intolerancia visceral para con lo que atrae a los otros.

4 Su estatus social queda evidenciado en la falta de dinero para poder comprar una casa nueva. Su marido indica: "Si Cristina se enteraba de que yo la había engañado [...] tendríamos que dejar la casa para irnos a vivir, tal vez, a Villa Urquiza, tal vez a Quilmes, de pensionistas en alguna de las casas donde nos prometieron darnos un lugarcito para construir ¿icon qué? (con basura, pues con mejores materiales no me alcanzaría el dinero) un cuarto y una cocina" ( $L a$ furia y otros cuentos 51).

5 Este indica: "Le hice notar que tenía un espejo roto en su cuarto y que por más que yo le insistiera la conveniencia de tirar los espejos rotos al agua [...] para quitarse la mala suerte, lo guardaba; que jamás temió que la luz de la casa bruscamente se apagara, y a pesar de que fuera un anuncio seguro de muerte, encendía con tranquilidad cualquier número de velas" (La furia y otros cuentos 49 ).

6 Los peces rojos también forman parte del decorado de la mansión descrita en "La Propiedad" que se encuentra, igualmente, en el libro La furia (1959): "En aquella mansión, en lugar de flores, peces rojos, que nadaban en sus peceras como Pedro por su casa, adornaban los dormitorios" (Ocampo, La furia y otros cuentos 100). 
En este sentido, el miedo a la enajenación -que impone limitaciones a la vida de Cristina- vuelve a hacerse presente en el momento de búsqueda de una "casa soñada": encontrarla resulta un tanto dificultoso de acuerdo con la superstición de que adquirir un hogar ya habitado llevaría a la protagonista a la alienación: "tuvimos que buscar un departamento nuevo, pues según sus creencias, el destino de los ocupantes anteriores influiría sobre su vida" (Ocampo, La furia y otros cuentos 50). Como en las novelas sentimentales ${ }^{7}$ ampliamente difundidas en Argentina en las primeras décadas del siglo XX, en este cuento el ideal de felicidad matrimonial está constantemente en juego porque, al menor contratiempo, puede quedar amenazado por la pobreza o la desigualdad económica de los personajes (Sarlo 115).

No obstante, los temores de la pareja se desvanecen frente a la compra de un inmueble que parece nuevo y parece de azúcar. Esas dos características de su apariencia hacen de él un lugar ideal: la "casa de nuestros sueños" (Ocampo, La furia y otros cuentos 50), imagen de la felicidad doméstica difundida por la cultura masiva a mediados del siglo XX. Su asociación con una figurita de azúcar ${ }^{8}$ la define no desde su funcionalidad sino desde los parámetros ornamentales y decorativos del kitsch dulce, acaramelado como los monumentos de azúcar de las vidrieras de la confitería (Moles, El kitsch 69). Sin embargo, antes de la compra, la propiedad tenía otro frente: "Esta casa parece de azúcar desde que la pintaron, llama la atención a todos los transeúntes. Pero a mí me gustaba más antes, con ese color rosado y romántico de las casas viejas" (La furia y otros cuentos 52 ). De modo que se establece una diferencia entre un antes y un después tanto en la vida de Cristina como en la fachada del inmueble. La renovación que le otorga a la casa la estética kitsch provoca placer y felicidad en los nuevos dueños y les permite olvidarse de sus respectivas supersticiones; el miedo a la alienación de ella: "Aquí se respira olor a limpio. Nadie podrá influir nuestras vidas y ensuciarlas con pensamientos que envician el aire" (50), y a la infelicidad en él: "Éramos tan felices, que

7 Definidas por Beatriz Sarlo como: "un modo estético de literatura cotidiana. Esto es: una de las formas posibles de la presencia de la ficción narrativa en el horizonte de expectativas del público medio y popular" (137).

8 Amícola observa que la cotidianeidad de Cristina aparece "defendida por los elementos del kitsch con los que establece un aparente mundo acogedor de una casa diminuta, como una casa de muñecas, pura y blanca como hecha de azúcar" ("La casa de azúcar" 231). 
a veces me daba miedo. Parecía que la tranquilidad nunca se rompería en aquella casa de azúcar" (50).

Lo cursi, dice Gómez de la Serna, tiene su primera explicación y antecedente en lo barroco (7). En el cuento "La propiedad", antes de la llegada del personaje de Ismael Gómez, la narradora ofrece una descripción recargada de los objetos exóticos que pueblan la mansión de campo donde trabajaba, percibida como un edén, la "mansión más bonita del continente" (Ocampo, La furia y otros cuentos 99): un jardín de cascadas, grutas, fuentes, glorietas, una habitación decorada con peces rojos; "Esta era una de las tantas originalidades de la patrona" (Ocampo, La furia y otros cuentos 99). Todos los objetos de la vivienda responden a una elección estética que la voz narrativa reconoce como "distinguida" y original, aunque a su vez ambas cualidades se contradicen con la acumulación excesiva que se evidencia irónicamente en la enumeración descriptiva. La ironía se expande también hacia la descripción de la propietaria: mientras que la empleada doméstica detalla fascinada la exhaustiva presencia de sus atributos positivos (generosa, bonita, rubia como el trigo y elegante), los comerciantes del barrio cuestionan su delgadez extrema, marca de distinción: "'tal vez un poquito delgada para su estatura', decía el panadero Ruiz y Langostino, el del muelle, que eran unos envidiosos" (Ocampo, La furia y otros cuentos 10o). Este puede identificarse como otro rasgo de distinción puesto que, como ha señalado Bourdieu, a medida que se sube en la jerarquía social, la proporción de consumos alimenticios disminuye, decrece la cantidad de alimentos pesados o grasos mientras que aumentan los consumos de alimentos que no hacen engordar (Bourdieu, La distinción 176).

En relación con esto, el antagonismo hiperbólico entre aumento y descenso acelerados del peso corporal, producto de comer "como un tiburón o como un pajarito" (Ocampo, La furia y otros cuentos 100), puede traducirse también en una tensión entre "digerir" y "tragar" a nivel cultural: la patrona no asimila los objetos culturales de manera medida, sino que primero los acumula en grandes cantidades para inmediatamente deshacerse de ellos, regalándoselos a su empleada, que pasa a ser la heredera legítima de todo lo que ella deja de usar por estar pasado de moda: al envejecer y estancarse, las normas estéticas descienden también en la

9 La distinción se evidencia también en el estatus social de las visitas a la casa: "Muchos huéspedes millonarios venían a alojarse y pasaban días, a veces semanas, a veces meses, en la casa" (La furia y otros cuentos 99). 
escala de la jerarquía social (Mukarovsky 46). La narradora afirma: "con verdadera pena, yo veía envejecer los trajes, los zapatos, los guantes, la ropa interior que [la señora] iba a regalarme" (Ocampo, La furia y otros cuentos 101); "Las mallas de baño, yo las estrenaba nuevecitas, porque el día que la señora las compraba ya le parecían horribles" (101). La posesión de todo lo que deja la propietaria es el motivo de felicidad de la heredera: "Yo era muy feliz en aquella vida de abundancia y de lujos" (Ocampo, La furia y otros cuentos 101). La desmesura en el consumo se traslada de esta manera a la servidumbre, que ostenta los bienes materiales de la burguesía. ${ }^{10}$

La patrona sigue los cánones de la moda no solamente en el vestir, sino también en los objetos decorativos del mobiliario, y en sus gustos alimenticios, que al quedar caducos son delegados a la empleada. Esta no solo disfruta de vacaciones, sino que incluso tiene permiso de hacerse cirugías estéticas gratuitas - a imitación de la señora, cuida su imagen y esculpe su cuerpo-, recibe los remedios vencidos y los postres mal hechos, come y bebe todo lo que desea, de modo que se presenta como un exponente de categoría que también consume, pero en nombre del ama, dando testimonio mediante su ociosidad y su carácter superfluo, de la magnificencia y riqueza de aquella (Baudrillard). En este cuento la propietaria vive una vida de abundancia y derroche que demuestra en los objetos y sujetos de su entorno hasta la llegada del personaje de Ismael Gómez. Como se ha observado, la presunta distinción en sus gustos se hace visible en varios aspectos: la alimentación, los objetos culturales, la vestimenta y los gastos. Por su parte, en "La casa de azúcar", antes de la intromisión de los otros, Cristina teme contagiarse de los gustos ajenos y siente cobijo en una casa cuyo frente "azucarado" aparenta responder a la estética kitsch. En este relato, el narrador marca un momento de cambio en la actitud de su esposa: "Parecía que la tranquilidad nunca se rompería [...], hasta que un llamado telefónico destruyó mi ilusión" (Ocampo, La furia y otros cuentos 50).

A medida que empiezan a llegar visitas inesperadas con productos de valor económico, Cristina va dejando de lado su gusto kitsch: la primera vez que tocan la puerta traen un vestido de terciopelo sobrio que

10 En este sentido, Veblen define como "consumo vicario" el consumo de alimentos, vestidos, habitación y mobiliario hecho por el personal que compone la comunidad doméstica de la clase ociosa (75). 
ella no hubiera podido pagar, ${ }^{11}$ en la segunda ocasión un perro de raza, y finalmente, se hace presente un hombre disfrazado de mujer que denuncia a la protagonista el robo de su amante. Este último personaje puede verse como uno de los indicios del progresivo trasvase de Cristina en otra persona. En medio de los reiterados toques a la puerta de entrada, el narrador de "La casa de azúcar" advierte que su esposa comienza a cambiar de costumbres y a cantar de una manera extraña, asimilándose a Violeta, la antigua dueña de la propiedad: "[Violeta] murió de envidia. Repetía [Cristina] sin cesar: 'Alguien me ha robado la vida, pero lo pagará muy caro. No tendré mi vestido de terciopelo, ella lo tendrá; Bruto será de ella; los hombres no se disfrazarán de mujeres para entrar en mi casa sino en la de ella" (Ocampo, La furia y otros cuentos 58 ).

El relato deja ver que la inclinación de Cristina hacia el lujo es lo que ocasiona la ruptura del ideal de felicidad matrimonial difundido por la cultura de masas (uno de cuyos exponentes eran las novelas sentimentales divulgadas por las revistas semanales de tirada masiva), manifiesto en la capacidad de contentarse con un horizonte económico y sentimental próximo y accesible (Sarlo 111). Hacia el final del cuento se nos revela que la adquisición de aquella casa, el objeto fetiche ${ }^{12}$ de la protagonista, cuya imagen prometía resguardo y una vida matrimonial feliz, termina siendo un motivo de alienación y de ruptura conyugal. De manera que, mediante la pérdida de supersticiones respecto de los gustos ajenos y el abandono progresivo de su felicidad kitsch, ${ }^{13}$ en las querellas con otros invasores que reclaman por Violeta, ${ }^{14}$ la protagonista adopta una nueva identidad.

11 - ¿Con qué dinero lo pagaste? -Mamá me regaló unos pe
nada, para no ofenderla" (La furia y otros cuentos 51).

12 vivida fuera de la domesticidad hogareña, signada por la relación con lo teatral y la exhibición del cuerpo y de la voz (Violeta era cantante), la cotidianeidad de Cristina aparecía, en cambio, defendida por los elementos del Kitsch con los que establece un aparente mundo acogedor de una casa diminuta, como una casa de muñecas, pura y blanca como hecha de azúcar" ("La casa de azúcar" 231).

13 En este sentido, Bourdieu señala que: "La intención de distinción aparece con el esteticismo pequeño burgués que, al hacer sus delicias de todos los sustitutivos pobres de los objetos y prácticas elegantes [...] se define contra la estética de las clases populares" (La distinción 56).

14 Como se observa en la siguiente cita: "-Violeta, escúcheme. [...] -No me llamo Violeta [...] Gracias, Violeta. -No me llamo Violeta. - ¿Cambió de nombre? Para nosotros usted es Violeta. 
Como en "La casa de azúcar, en "La propiedad", la narradora también marca un giro en la historia: "Todo cambió cuando llegó Ismael Gómez" (Ocampo, La furia y otros cuentos 101). Ante la aparición del recién llegado se modifican dos de los aspectos que definían la actitud distinguida de la señora: en primera instancia, deja de regalar a la criada todo lo que le sobra y comienza a acumular los objetos que, una vez comprados, irán envejeciendo ${ }^{15}$ - "Ismael Gómez pretendía que cuanto más viejo era un traje o un remedio sentaba mejor" (Ocampo, La furia y otros cuentos 101). En segunda instancia cambia su dieta incesante de aumento y descenso de peso por un régimen basado en el acopio de azúcares: "Las comidas también cambiaron: me obligaron a preparar muchos postres con crema y huevo batido, mucho merengue con dulce de leche y yemas quemadas, que me hacían mal al hígado" (Ocampo, La furia y otros cuentos 101). Esto puede relacionarse con lo que Gómez de la Serna ha definido como "cursi malo", es decir, el acto de "abundar en lo que sin abundancia está bien, empalagar con lo que en su sombría dulzura es noble, convertir en zalamería lo que en su notoria sobriedad sería un encanto [...]. La redundancia de lo cursi es lo que mata" (26-27). Los hábitos y costumbres de la dueña de la mansión pasan a obedecer las normas del gusto impuestas por el huésped, quien lleva al extremo una suma de paradójicos cuidados fatales mediante los cuales termina convirtiéndose, una vez que ella muere, en el

Siempre la misma misteriosa Violeta" (La furia y otros cuentos 53). "-Si usted vuelve a ver a Daniel, lo pagará muy caro, Violeta. -No sé quién es Daniel y no me llamo Violeta" (55).

15 Un antecedente de la acumulación kitsch puede verse en el cuento "Los pies desnudos" (Viaje olvidado, 1937) en el que un personaje femenino guarda todo, pero al mismo tiempo vive en la perpetua angustia de haber perdido todo, ante lo cual teme morir asfixiado por la gran cantidad de objetos que rodean su vida y de los que no puede deshacerse. En "Los objetos" (La furia, 1959) se hace presente esa misma asfixia ante una superpoblación de objetos fetiches reencontrados por la protagonista, que convierten su cuarto en un infierno. Como desenlace, en este cuento la felicidad del reencuentro posesivo se transforma en obsesión y horror: "[Camila Ersky] Vio que los objetos tenían caras, esas horribles caras que se les forman cuando los hemos mirado durante mucho tiempo" ( $L a$ furia y otros cuentos 108). Por su parte, en "Informe del cielo y del infierno" (La furia, 1959) los objetos que pueblan la cultura masiva y consumista pasan a invadir el mundo de ultratumba: "A ejemplo de las grandes casas de remate, el cielo y el infierno contienen en sus galerías hacinamientos de objetos" (La furia y otros cuentos 225). El narrador de este cuento señala con una mirada irónica las ofertas de ángeles y demonios como si fueran vendedores de productos, indicando que en el momento de la muerte cada hombre deberá elegir ciertos objetos que determinarán si irá al cielo o al infierno. 
nuevo dueño de la propiedad. Encontramos aquí una lucha de gustos en la que se puede interpretar que la apropiación de los "recién llegados" adquiere una connotación no solo individual sino también social en el contexto de expansión de la cultura de masas.

\section{Las metáforas alimenticias como indicios del cambio}

En el momento de describir los cambios del kitsch al "refinamiento" en Cristina, el marido observa que la protagonista de "La casa de azúcar" deja de adornar "periódicamente la casa con volantes de nylon en las tapas de la letrina, en las repisas del comedor, en todas partes, como era su costumbre" (Ocampo, La furia y otros cuentos 51). Esa envoltura teatral y barroca de la propiedad doméstica implica una redundancia: todo se encuentra cuidado y enmarcado, de modo que no solo se trata de poseer, sino de subrayar dos y tres veces lo que se posee, una de las obsesiones del pequeño propietario urbano o suburbano (Baudrillard 52).

Por otro lado, cuando la protagonista de "La casa de azúcar" pasa a tener gustos distinguidos, el narrador hace referencia a la pérdida de ese placer kitsch, asociado principalmente con la comida: "[Cristina] Ya no preparaba esos ricos postres, un poco pesados, a base de cremas batidas y chocolate" (Ocampo, La furia y otros cuentos 51). Este aspecto que en el cuento se ve como parte de la identidad perdida de Cristina tras la llegada de los invasores, en "La propiedad" es el factor de cambio de la señora, después de que, por consejo de su huésped, decide contratar un nuevo cocinero: "En aquella época la señora tomó a su servicio a un cocinero gigante, recomendado por Ismael Gómez [...]. Las comidas cambiaron de nuevo. Enormes postres de cuatro pisos, adornados con figuras aparentemente alegres, desfilaban [...] por el comedor" (Ocampo, La furia y otros cuentos 102; subrayado nuestro). Como en el frente de "La casa de azúcar", en estas preparaciones culinarias cobra más importancia lo que fingen ser que lo que realmente son. La decoración colosal y pesada puede asociarse con lo que Barthes ha definido como "cocina ornamental", esto es, una cocina exclusivamente para la vista que presenta una perseverancia en la cobertura como una exigencia de distinción, pero sobre todo para preparar y sostener la ornamentación (131-132). La comida en este caso perdería su funcionalidad a merced de la belleza visual del plato, estableciendo una nueva tensión entre ser y parecer.

La presencia de productos alimenticios para la vista, pesados y azucarados, es un aspecto que se reitera en varios cuentos de Silvina Ocampo. 
En "Los Amantes" (Las invitadas, 1961) la ansiedad del encuentro amoroso es trabajada a partir de un banquete de ocho tortas, en el que el narrador describe la composición de cada una de ellas ${ }^{16}$ y el ritual en el que los enamorados devoran cada tajada antes de hacer el amor: "Ella abrió el paquete y sacó la bandeja de cartón donde brillaban, un poco aplastados ya, la crema, el merengue y el chocolate [...] Mascaban al unísono y terminaban de deglutir cada bocado al mismo tiempo" (Ocampo, Las invitadas 125). Silvina Ocampo ha señalado que para la descripción de las tortas en este cuento se había inspirado en las creaciones de una señora que se dedicaba a hacer repostería: "realmente hace unos postres que son cuadros, no postres, a uno le da lástima comer esas cosas: una canasta, un pajarito, un angelito" (Ulla, Encuentros con Silvina Ocampo 23). En este sentido, los cuentos dejan ver cómo los alimentos de la cocina ornamental pierden su naturaleza primaria a favor de una decoración que pretende huir de su estado natural originario gracias a una suerte de barroco (Barthes 132); en "Los amantes" el narrador señala: "la tercera tajada de torta, más opulenta que las otras, parecía el material que sirve para construir algunas casas originales que hay en los balnearios" (Las invitadas 126). Se observa pues en la descripción de los alimentos algunos aspectos propios de la estética kitsch: superficies cubiertas con ornamentos, abundancia de "colores sentimentales" (rosas, pasteles), e incorporación de materiales que rara vez se presentan tal cual son.

La pretendida distinción en las mujeres pertenecientes a la pequeña burguesía también se evidencia en "La gallina de membrillo" (Las invitadas, 1961), un cuento en el cual: "Manuel Grasín, que trabajaba en la confitería 'El Obelisco', una vez por semana le traía [a Blanquita Simara, el perro de la protagonista] una bolsa de sobras: huesos, pasteles rotos, grasa rancia de jamón y pavo, sándwiches viejos" (Ocampo, Las invitadas 155). La protagonista de este relato es una mujer casada a quien su marido abandona, situación que la impulsa a dejar de lado su posición de "niña mimada de la sociedad" (15), para ponerse al mando de un taller de costura. No obstante, conserva sus gustos distinguidos en la ostentación de las

16 En relación con esto, Ulla observa que lejos de la enumeración ingenua, esta enumeración de pasteles "tiende a provocar el empalago, meta que se propone alcanzar el narrador para poner énfasis en la rusticidad de la pareja de amantes, que después de comer hasta el hartazgo, hará el amor" (Invenciones a dos voces 192). 
comodidades modernas de su casa ${ }^{17}$ y en la enumeración de las comidas que le gustan (según ella, las más caras): "langostinos, blanquito de pavita, pastel de almendras, faisán a la turca, dátiles y marrón glasé, caviar, que es difícil de conseguir" (Ocampo, Las invitadas 158). La ornamentación barroca de los alimentos y la acumulación de ingredientes heterogéneos deja en evidencia los criterios que caracterizan al kitsch: amontonamiento y antifuncionalidad en pos de la ornamentación (Moles El kitsch).

Por otro lado, las metáforas alimenticias en el discurso de los personajes ponen al descubierto la ironía en la distancia que se establece entre lo que ellos dicen y lo que hacen: en "La casa de azúcar", si bien Cristina aparentemente deja de lado sus costumbres para imitar el modo de vida de Violeta, irónicamente conserva en su discurso algunos rasgos del kitsch dulce: "si una persona hubiera vivido en esta casa, esa persona tendría que ser como esas figuritas de azúcar que hay en los postres o en las tortas de cumpleaños: una persona dulce como el azúcar" (Ocampo, La furia y otros cuentos 55). Asimismo, ante su cambio de personalidad se observa la aceptación de todo aquello que antes se expresaba en supersticiones, mediante un nuevo placer gustativo: "Canto con una voz que no es mía [...] antes me hubiera afligido, pero ahora me deleita. Soy otra persona, tal vez más feliz que yo" (Ocampo, La furia y otros cuentos 57; subrayado nuestro). En "La propiedad" la mirada narrativa hacia Ismael también se trabaja mediante una contraposición de metáforas alimenticias: "La gente decía que era un pan de Dios, pero yo no lo tragaba" (Ocampo, La furia y otros cuentos 101). Esta característica, sumada a los cambios que ocasiona en la actitud de la señora, hacen que el intruso sea presentado como un "vividor", esto es: aquel a quien le gusta comer bien y beber bien, pero también aquel que sabe entrar en la relación familiar que el beber y el comer en común favorecen y simbolizan, y en la que desaparecen las reservas que manifiestan la distancia con el rechazo de mezclarse y de abandonarse (Bourdieu, La distinción 179). Por otro lado, los postres que en "La propiedad" forman parte de los nuevos gustos alimenticios de la señora se describen de manera ambigua, oscilando entre el kitsch dulce y el kitsch agrio, que según Moles retraducen la oposición freudiana entre el instinto

17 La protagonista de este cuento señala: "Somos románticas, nos gusta vivir con las comodidades modernas. Ya ve usted que tenemos en nuestra casita todas las máquinas, desde la licuadora hasta el televisor. Nos gusta vivir bien, entre adornos bonitos, perros de porcelana y ¿para qué ocultarlo?, somos gastadoras" (Las invitadas 159). 
sexual y el instinto de muerte, principio de placer de la construcción y de la destrucción (El Kitsch 69): "con el tiempo descubrí que esas figuras hechas de merengue rosado, que en el primer momento parecían tan bonitas, representaban calaveras, monstruos con cuatro cabezas, diablos con guadañas, todo un mundo de cosas horribles." (Ocampo, La furia y otros cuentos 102). La conversión de los postres azucarados en figuras monstruosas ${ }^{18}$ coincide con uno de los elementos del kitsch agrio: los cráneos mexicanos de azúcar (Moles, El Kitsch. El arte de la felicidad 69).

De manera que en estos cuentos, el placer kitsch se presenta no solo en los objetos de consumo, sino también en la descripción de comidas dulces ${ }^{19}$ pautada por una inadecuación, en tanto prima en ellas la ornamentación sobre la función alimenticia. El cambio en los gustos culinarios es uno de los principales indicios del traslado de la estética kitsch hacia la distinguida en "La casa de azúcar" y del camino inverso en "La propiedad". Esto lleva al desenlace fatal que se evidencia en la supremacía del personaje intruso sobre la identidad de la propietaria: en "La casa de azúcar" tras una sucesión de enigmas, Cristina pierde sus costumbres para adoptar las de Violeta: pasa a convertirse en la antigua dueña; en "La

18 La ambigüedad entre placer degustativo y muerte, que implica asimismo la ambigüedad entre la apariencia ostentosa de la comida y lo que verdaderamente es, se puede ver también en "El crimen perfecto" (Las invitadas, 1961), cuento en el que Gilberta Pax describe la relación de amor-odio que mantiene con su cocinero: en un primer momento, ella y su familia detestaban los platos decorativos pero de mal gusto que realizaba el chef; por eso mismo la protagonista decide seducir a este último para que haga mejor su labor -Gilberta señala: "Me vino la idea de sacrificarme por mi deber de ama de casa y seducirlo" (Las invitadas 173)-. Como consecuencia, mientras el resto de la familia sufría de dolores estomacales, el cocinero preparaba manjares y postres de merengue solo para ella, como demostración de su enamoramiento. En segunda instancia, una discusión en torno a los hongos (comida que Gilberta detestaba, pero que su familia deseaba degustar y el cocinero no podía comprar por su alto valor económico) termina de resquebrajar la relación entre el ama de casa y el chef. Tras conocer esta historia, el amante de la protagonista realiza un plan perfecto para matar a los comensales: vende al chef hongos envenenados a buen precio. La muerte de la familia y del cocinero después de consumir las setas termina siendo noticia en los periódicos.

19 En cuanto a la tensión entre kitsch dulce y kitsch agrio, Amícola ha observado en su análisis de "La casa de azúcar" que: "en tanto la casa es de azúcar y de almibaramiento de repostería, ella representa, en el fondo, un señuelo o una fachada que oculta una capa diferente de la realidad. Sin embargo, lo monstruoso de lo excesivamente azucarado sugiere, al mismo tiempo, un exceso Kitsch" ("La casa de azúcar" 238). 
propiedad", como consecuencia de la misteriosa muerte de la patrona, el "recién llegado" termina siendo el nuevo señor de la mansión.

\section{La satisfacción de matar a los intrusos}

Como en "La propiedad", el decorado de la mansión del cuento "Las esclavas de las criadas" responde a un barroquismo en el que se superponen una sobreabundancia de señoras, flores, animales embalsamados y regalos para la enferma, quien en su habitación también guarda una colección innumerable de objetos: "En su cuarto atestado de cuadros, en el lugar privilegiado, estaba el retrato de Herminia [la criada], vestida de Manola" (Ocampo, Los días de la noche 6o). Frente a todos ellos, la criada siente felicidad: "A Herminia le gustaban los trabajos en la casa de la Señora de Bersi. El tigre embalsamado tenía cepillo especial para sus dientes, y las teclas del piano también; el cupido de mármol, una esponja, y las palomas de plata, un pincel" (62).

En la descripción abundante de los nuevos objetos y sujetos que ingresan a la casa, el narrador, testigo impersonal de los acontecimientos -en ninguna parte de su relato se da a conocer, tampoco da marcas de género, aunque de acuerdo con el contexto de la historia puede suponerse que se trata de una mujer-, se detiene por un lado en la descripción de los obsequios kitsch que las señoras dan a Herminia como una estrategia de conquista: "las visitas le traían chocolate en una caja pintada con gatos, o pancitos de salud en una canastita de material plástico, o empanadas con dulce de membrillo en una valijita que decía Buen Viaje, o jalea de naranja en una polvera de vidrio con algunos pelos" (Ocampo, Los días de la noche $60)$. En estos regalos podemos observar nuevamente una conjunción entre comida dulce y envoltorio kitsch.

Por otro lado, el narrador trabaja polifónicamente con el caudal de voces femeninas emitidas por las visitas, discursos que tienen como contenido bien la desvalorización de la vida de la señora, ${ }^{20}$ bien la desestimación de los regalos que ella recibe, ${ }^{21}$ o bien la necesidad de una buena

20 "Algunas dijeron: ${ }_{\mathrm{i}}$ No le parece, doctor, que prolongar la vida de una señora que sufre tanto es un... una falta de humanidad?" (64-65).

21 "-Sólo un muerto recibe tantos ramos -comentaba una de las visitas [...] -No es sano respirar el olor de tantas flores -decía otra" (60). 
criada. ${ }^{22}$ Tanto en la descripción de los objetos que entran en la casa como en la cita de las voces intrusas, la identidad se pierde en la cantidad, en su carácter masivo: no se particularizan los nombres de las dueñas de los regalos ni de las frases, sino que un mismo alegato se repite en varias bocas y un mismo tipo de obsequio comestible -los dulces- redunda en distintos envoltorios.

Este discurso general de las visitas solo va a tomar un cierto grado de particularidad e identidad en la propuesta de trabajo a Herminia. Cuatro son los personajes que le ofrecen empleo en sus respectivas casas una vez que muera la patrona: Tuco Bersi -el hijo de la propietaria-, Alma Montesón, Lilian Guevara y Lina Grundic. No obstante, todos los ofrecimientos usan el mismo enunciado compuesto por proposiciones de un mejor pasar económico y un modelo de vida que emula el lujo difundido por la prensa masiva: "tengo una casa preciosa que usted habrá visto tal vez fotografiada en El Hogar o en el retrograbado de La Nación" (Ocampo, Los días de la noche 63); en esta propuesta nuevamente puede verse cómo la vida suntuosa del patrón pretende ser correspondida con la de los sujetos de su pertenencia a los fines de que estos por su lujo testimonien la legitimidad o el privilegio social del amo (Baudrillard 39).

A diferencia de "La casa de azúcar" y "La propiedad" -cuentos en los que los "intrusos" logran cambiar los gustos y las costumbres de las propietarias e incluso convertirse en sus herederos-, en "Las esclavas de las criadas", ante el intento del grupo de gente que entra a la mansión para apoderarse de las pertenencias (el narrador observa sin asombro cómo la protagonista incluye en la categoría de intruso al propio hijo de la señora de Bersi, quien debiera ser heredero legítimo de sus bienes), el horror de la empleada doméstica ${ }^{23}$ acarrea como consecuencia la muerte de cada uno de los que han aspirado a tomarla como herencia: Tuco Bersi muere en el intento de llevarse el piano, aplastado por el instrumento que pretendía heredar; Alma Montesón fallece de un ataque cardíaco, Lilian Guevara en un accidente automovilístico, Lina Grundic tiene una muerte misteriosa

22 "A cada rato [Herminia] las sorprendía diciendo: -Somos esclavas de nuestras criadas, confesémoslo. -La muchacha se me fue. O bien: -La muchacha que tengo es malísima" (61).

23 Herminia siente espanto hacia las propuestas: " ${ }_{\mathrm{C}} \mathrm{iNo}$ se vendría conmigo, preciosa? Herminia, ante la monstruosa proposición, se hizo la sorda y no contestó nada" (62). "Herminia quedó asombrada. No podía creer que esta muchacha joven [Lilian Guevara] le hablara en esos términos tan vulgares. Por no llorar, se echó a reír con frenesî” (64). 
en el ascensor de su casa. El anuncio de estas fatalidades inmediatamente después de la propuesta de trabajo liga de manera implícita a Herminia con el acto criminal, que aparece relatado mediante un discurso aún más impersonal que el del narrador testigo: la prensa escrita y radiofónica hacen de la vida privada de la empleada un relato público de llegada masiva. La muerte de los intrusos devuelve a Herminia el carácter de heredera legítima de los bienes de la señora, así como también restituye la vida a la propietaria: "este milagro de la longevidad se lo debía a Herminia, así lo confesó ella misma a los cronistas" (Ocampo, Los días de la noche 67). De esta manera, en este cuento lo masivo se entromete en la vida privada de los personajes mediante la acumulación de objetos kitsch, la repetición de frases hechas y clichés, el discurso de la prensa escrita y radiofónica.

En estos cuentos la vida pública se entromete en la propiedad privada de sus dueños, bien de manera multitudinaria o impersonal, como en "La casa de azúcar" y "Las esclavas de las criadas", o bien en manos de un representante de los "recién llegados", como en "La propiedad". En los tres relatos las visitas al hogar tienen un nivel de seducción que puede asimilarse al de la cultura de masas: hacen uso de los códigos familiares expresados en clichés, kitsch y formas estereotipadas, con los que construyen una ilusión emocional. Los invasores aspiran a heredar las pertenencias de las propietarias "legítimas" ocasionando un cambio en sus gustos y costumbres. Todos producen sentidos ambiguos que por un lado plantean un ideal de felicidad estereotipado, traducido en imágenes de lo socialmente establecido como la "casa soñada", el "matrimonio perfecto", la "felicidad cotidiana". Estas imágenes cristalizadas en los discursos vinculados a la cultura de masas, como la prensa o la novela semanal, esconden un desenlace de horror, muerte o alienación que, como hemos visto, es un factor que rompe con la rigidez del estereotipo. En este sentido, hay una estrecha relación entre propiedad, gusto y cultura de masas, vínculo en el que la oscilación entre "distinción" y trivialidad, lujo y pobreza, belleza y fealdad en el mobiliario, en los objetos que forman parte de él, en la vestimenta y en los gustos de los personajes, insinúa una objetivación de las relaciones sociales en los objetos familiares y el juego entre la "legalidad" de los poseedores legítimos y la imitación o admiración de los "recién llegados". 


\section{Obras citadas}

Amícola, José. Camp y posvanguardia. Manifestaciones culturales de un siglo fenecido. Buenos Aires: Paidós, 2000. Impreso.

Amícola, José. "La casa de azúcar y el placer de sentirse cruel y ser mujer (Buenos Aires, 1959)". La batalla de los géneros. Novela gótica versus novela de educación. Rosario: Beatriz Viterbo, 2003. Impreso.

Amossy, Ruth y Anne Herschberg Pierrot. Estereotipos y clichés. Buenos Aires: Eudeba, 2001. Impreso.

Barthes, Roland. Mitologías. México: Siglo XXI, 1991. Impreso.

Baudrillard, Jean. "La moral de los objetos. Función-signo y lógica de clase". Los objetos. Ed. Abraham Moles. Buenos Aires: Tiempo contemporáneo, 1969. Impreso.

Bourdieu, Pierre. El sentido social del gusto. Buenos Aires: Siglo XXI, 2010. Impreso.

Bourdieu, Pierre. La distinción. Criterios y bases sociales del gusto. Madrid: Taurus, 2000. Impreso.

Gómez de la Serna, Ramón. "Lo cursi". Lo cursi y otros ensayos. Buenos Aires: Sudamericana, 1943. Impreso.

Mancini, Adriana. Escalas de pasión. Buenos Aires: Norma, 2003. Impreso.

Mancini, Adriana. "Silvina Ocampo: la literatura del 'Dudar del Arte". Historia crítica de la literatura argentina. Tomo 9: El oficio se afirma. Dir. Noé Jitrik. Buenos Aires: Emecé, 2004. 229-251. Impreso.

Mascioto, María de los Ángeles. Sociedad y cultura de masas en la cuentística de Silvina Ocampo (1959-1970). Tesis de Licenciatura en Letras.

La Plata: Universidad Nacional de La Plata, 2010. Impreso.

Moles, Abraham. El Kitsch. El arte de la felicidad. Buenos Aires: Paidós, 1973. Impreso.

Moles, Abraham y otros. Los objetos. Buenos Aires: Tiempo contemporáneo, 1969. Impreso.

Molloy, Sylvia. "Simplicidad inquietante en los relatos de Silvina Ocampo". Lexis II.2 (1978): 241-251. Impreso.

Mukarovsky, Jan. Escritos de Estética y Semiótica del Arte. Barcelona: Gustavo Gili, 1977. Impreso.

Ocampo, Silvina. La furia y otros cuentos (Prol. Enrique Pezzoni). Madrid: Alianza, 1982. Impreso.

Ocampo, Silvina. Las invitadas. Buenos Aires: Orión, 1979. Impreso.

Ocampo, Silvina. Los días de la noche. Madrid: Alianza, 1984. Impreso.

Sarlo, Beatriz. El imperio de los sentimientos. Narraciones

de circulación periódica en la Argentina (1917-1927).

Buenos Aires: Catálogos, 1985. Impreso. 
Ulla, Noemí. Encuentros con Silvina Ocampo. Buenos

Aires: Editorial de Belgrano, 1982. Impreso.

Ulla, Noemí. Invenciones a dos voces. Ficción y poesía en Silvina

Ocampo. Buenos Aires: Ediciones del Valle, 200o. Impreso.

Veblen, Thorstein. Teoría de la clase ociosa. México:

Fondo de Cultura Económica, 1966. Impreso.

Zubieta, Ana María. Humor, nación y diferencias. Arturo Cáncela y

Leopoldo Marechal. Rosario: Beatriz Viterbo, 1995. Impreso. 